\title{
A novel proposal to address the future of penile prosthetics: are we currently focused in the wrong direction?
}

\author{
Jason R. Kovac \\ Men's Health Center, Indianapolis, Indiana, USA \\ Correspondence to: Dr. Jason R. Kovac, MD, PhD, FACS, FRCSC. Men's Health Center, 8240 Naab Road, Suite 220, Indianapolis, Indiana 46260, \\ USA. Email: jkovac@urologyin.com. \\ Comment on: Rodriguez KM, Kohn TP, Davis AB, et al. Penile implants: a look into the future. Transl Androl Urol 2017;6:S860-6.
}

Submitted Nov 13, 2017. Accepted for publication Nov 13, 2017.

doi: $10.21037 /$ tau.2017.11.18

View this article at: http://dx.doi.org/10.21037/tau.2017.11.18

The future of penile prosthesis has been debated and postulated for decades. An excellent summary by Rodriguez et al. (1) in this issue of Translational Andrology and Urology describes nicely the history of the modern inflatable penile prosthesis while capturing possible future advances in rigidity, shape, composition and activation. The authors pose excellent questions and highlight technologies that may shape the future of advanced penile prosthetics in years to come. The development of new $3 \mathrm{D}$ models to individualize treatment, the removal of the reservoir as well as alterations to the materials required to cause inflation are all well addressed (1).

When one looks back almost a decade, reviews of novel technological advances were focused on suggestions that were very similar to those proposed today. For example, Simmons and Montague (2) in 2008 suggested improvements nearly identical (with a few differences) to those suggested by Rodriguez et al. (1). Thus, urologic surgeons are largely left at the mercy of the major penile prosthetic manufacturers to advance an industry that perhaps, as they might see it, does not require much advancement at all.

The penile prosthetic industry, as it is today, is currently profitable using a device that has been in practice for decades, is safe, already approved and uses well accepted and researched materials. What then is the impetus for change? Given that there are only two major industrial players, minimal steps forward in device, pump technologies and cylinder shapes may be all that is needed to keep up the appearances of innovation.

The most likely next major advance will come from whatever technology incorporates 3-piece functionality into a 1-piece (corporal cylinders only) device. While presumably both American Medical Systems/Boston Scientific and Coloplast are working towards making this a reality, we are still decades away from this type of technological 'tour-deforce'. Thus, for the time being, it may be possible that the industry as a whole is looking in the wrong direction.

Consider for a moment, that perhaps the future of penile prosthetic urology revolves around not just improved awareness and acceptance but mainly, and most importantly, financial accessibility. The lattermost of these factors should underscore the real motivation for manufacturers. So, while upward innovation is necessary, the real future evolution should be the creation of a low cost, no frills device that is cheap, reliable, safe, and easy to use. Such a device should use existing materials wherever possible to keep that research pipeline costs low. The device must be easy to implant so it can be done in the outpatient setting with a quick return to work.

Interestingly, such a device already exists-the malleable penile prosthesis. While the current one-piece devices are not perfect, they are not as prone to mechanical failure as the inflatable devices. Furthermore, since stretched penile length is usually the maximum length possible, men would likely consider a device that would make them as "full" as possible all the time. As such, it seems that only small changes to the device length, girth options and malleability are all that are keeping the malleable prosthesis from satisfying most of the criteria stated above. Once those have been addressed, the only ceiling that remains is cost. If that could be brought down to allow the device to be inserted at a minimal financial 
outlay, the industry would be revolutionized-at least until the next major advance arrives.

\section{Acknowledgements}

None.

\section{Footnote}

Conflicts of Interest: The author has no conflicts of interest to

Cite this article as: Kovac JR. A novel proposal to address the future of penile prosthetics: are we currently focused in the wrong direction? Transl Androl Urol 2017;6(Suppl 5):S867S868. doi: 10.21037/tau.2017.11.18 declare.

\section{References}

1. Rodriguez KM, Kohn TP, Davis AB, et al. Penile implants: a look into the future. Transl Androl Urol 2017;6:S860-6.

2. Simmons M, Montague DK. Penile prosthesis implantation: past, present and future. Int J Impot Res 2008;20:437-44. 